University of Texas Rio Grande Valley

ScholarWorks @ UTRGV

\title{
Considering Ethnicity and Gender Effects in Disgust Propensity and Spider and Snake Phobia: Comparing Asian Americans and European Americans
}

\author{
Laura L. Vernon \\ Florida Atlantic University \\ Michiyo Hirai \\ The University of Texas Rio Grande Valley, michiyo.hirai@utrgv.edu
}

Follow this and additional works at: https://scholarworks.utrgv.edu/psy_fac

Part of the Psychology Commons

\section{Recommended Citation}

Vernon, L. L., \& Hirai, M. (2012). Considering Ethnicity and Gender Effects in Disgust Propensity and Spider and Snake Phobia: Comparing Asian Americans and European Americans. Journal of Experimental Psychopathology, 409-422. https://doi.org/10.5127/jep.015911

This Article is brought to you for free and open access by the College of Liberal Arts at ScholarWorks @ UTRGV. It has been accepted for inclusion in Psychological Science Faculty Publications and Presentations by an authorized administrator of ScholarWorks @ UTRGV. For more information, please contact justin.white@utrgv.edu, william.flores01@utrgv.edu. 


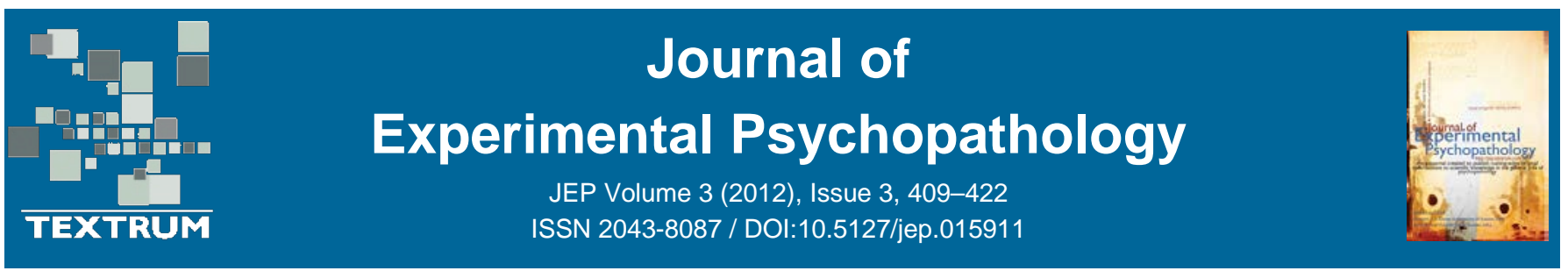

\section{Considering Ethnicity and Gender Effects in Disgust Propensity and Spider and Snake Phobia: Comparing Asian Americans and European Americans}

\section{Laura L. Vernon ${ }^{\mathrm{a}}$ and Michiyo Hirai ${ }^{\mathrm{b}}$}

a. Florida Atlantic University

b. University of Texas Pan American

\section{Abstract}

This study examined ethnic and gender differences and ethnicity by gender interactions in disgust propensity, spider and snake phobic distress, and their interrelationships. A main effect for ethnicity was found, with Asian Americans $(n=219)$ reporting more disgust propensity and phobic distress than European Americans $(n=581)$. Gender effects were modified by ethnicity by gender interactions, with European American males reporting the least disgust propensity and distress, and gender differences present only for European Americans. For both ethnic groups, phobic distress scores were strongly correlated with animal and non-animal disgust propensity. In hierarchical regression analyses, animal disgust propensity was uniquely related to spider and snake distress scores among both ethnic groups, although non-animal disgust propensity was only a significant individual predictor among European Americans. The results suggest that models of animal phobia and disgust propensity based on European American samples cannot be uniformly applied to Asian Americans. Ethnicity and gender, and their interaction, may influence the intensity of disgust propensity and animal phobic distress and their relationships with one another.

(C) Copyright 2012 Textrum Ltd. All rights reserved.

Keywords: Disgust, Specific Phobia, Spider, Snake, Cross-cultural, Asian Americans

Correspondence to: Laura L. Vernon, Wilkes Honors College, Florida Atlantic University, 5353 Parkside Drive, Jupiter, FL 33458, USA. Telephone: (561)799-8411. Fax: (561)799-8412. Electronic mail: Ivernon@fau.edu

1. Wilkes Honors College, Florida Atlantic University, 5353 Parkside Drive, Jupiter, FL 33458, USA.

2. University of Texas Pan American

Received 07-Mar-2011; received in revised form 03-Nov-2011; accepted 05-Dec-2011 


\section{Table of Contents}

Introduction

Disgust Propensity and Animal Phobic Distress

Ethnic and Gender Influences on Disgust and Animal Phobic Distress

Hypotheses

Method

Participants

Procedure

Measures

Results

Ethnicity and Gender Differences

Correlations of Disgust Propensity with Spider and Snake Phobic Distress

Independent Relationships of Disgust Propensity with Spider and Snake Phobic Distress

Discussion

References

\section{Introduction}

Important strides are being made in cross-cultural emotion and psychopathology research. Several studies have found ethnicity and gender differences in emotion (Eid \& Diener, 2001; Mesquita \& Frijda, 1992). Also, a few ethnicity by gender interactions have been observed, which suggest that ethnic group membership may influence the existence and magnitude of gender differences in emotion (Brody, 1997; Hirai \& Vernon, 2011). In light of evidence suggesting that emotion plays a role in many forms of psychopathology (Berenbaum, Raghavan, Le, Vernon, \& Gomez, 2003), it seems likely that ethnicity and gender would influence the role of specific emotions within various forms of psychopathology. Despite the growing body of work examining gender or ethnicity effects on emotion or on psychopathology alone, relatively little is yet known about the complex intersection of ethnicity, gender, emotion, and psychopathology. The current study is the first to focus concurrently on these four areas: disgust propensity, animal phobic distress, ethnicity, and gender.

\section{Disgust Propensity and Animal Phobic Distress}

There is evidence that trait disgust, termed disgust propensity by van Overveld, de Jong, Peters, Cavanagh, and Davey (2006), is related to spider phobia (e.g., de Jong \& Merckelbach, 1998; Tolin, Lohr, Sawchuk, \& Lee, 1997; Vernon \& Berenbaum, 2002). Given such findings, rather than the fearbased terminology of spider "fearful" and "phobic", the current paper will refer to spider "distress", following Vernon and Berenbaum (2002, 2008).

Spider distressed individuals report more disgust propensity to the animal domain (e.g., spiders, slugs, cats) and several other disgust elicitor domains such as body products than do non-distressed individuals (Tolin et al., 1997). Only two studies have examined the relative contributions of different disgust propensity domains to spider distress. Regression analyses in these studies indicated that the association between animal disgust propensity and spider distress appears to be independent of other disgust propensity domains and of trait anxiety and fear propensity (de Jong \& Merckelbach, 1998; Vernon \& Berenbaum, 2008). However, non-animal disgust propensity was not uniquely associated with spider distress when controlling for these other variables (de Jong \& Merckelbach, 1998; Vernon \& Berenbaum, 2008).

Although links between spider distress and disgust propensity have been reasonably well-established, only one study to date has examined disgust propensity in relation to snake distress: Klieger and Siejak 
(1997) found a positive relationship between snake distress and food-related disgust propensity. Research has not yet examined the extent to which snake distress is independently associated with animal and non-animal disgust propensity.

\section{Ethnic and Gender Influences on Disgust and Animal Phobic Distress}

Given the relatively high 12-month prevalence rate of $8.7 \%$ in the US for specific phobia (Kessler, Chiu, Demler, \& Walters, 2005) and the potential for impairment (Wells et al., 2006), it is important that mental health professionals increase our understanding of specific phobia symptoms and related emotional processes in different cultural and ethnic groups. Asian Americans may be particularly important to study as they represent the most rapidly growing ethnic group in the US (U.S. Census Bureau, 2010). Unfortunately, our knowledge about anxiety disorders, including specific phobia, in Asian American populations is scant. Although no research has examined ethnic differences in snake or spider distress specifically, two studies suggest the potential influence of ethnic and cultural group membership on animal-related anxiety. A preliminary study in New Zealand found that participants of Asian descent $(n=$ 24) scored significantly higher than did participants of European descent $(n=82)$ on a short phobic anxiety subscale (Barker-Collo, 2003). Further, Davey et al. (1998) found that mean fear ratings of 51 animals was higher in Hong Kong and Japan than the US. Davey et al. also reported fear ratings to specific animals suggestive of differences between Asian and western samples (e.g., Japanese rated spiders as more frightening than Americans). These studies provide preliminary evidence for potential cultural and ethnic differences in animal distress.

Concerning gender differences, there are some reports that in Western samples women endorse more animal distress symptoms than men (e.g., Fredrikson, Annas, Fischer, \& Wik, 1996; Klorman, Weerts, Hastings, Melamed, \& Lang, 1974). Asian Americans have not been investigated in this regard.

Disgust propensity is thought to be strongly influenced by ethnic and cultural socialization practices (Rozin \& Fallon, 1987); however, there have been few empirical investigations of ethnicity and gender effects on disgust propensity and animal phobic distress and their interrelationships. There is evidence for several cross-cultural similarities concerning the experience and expression of disgust. For example, when summed across data collected in 37 countries, Scherer and Walbott (1994) found that disgust experiences were reported as frequent, short-lived, low in arousal, and fairly freely expressed. International comparisons of American and Asian samples specifically suggest similarities in both the potential elicitors of disgust and the meanings attributed to disgusting stimuli and events (Brandt \& Boucher, 1985; Boucher \& Brandt, 1981; Haidt, Rozin, McCauley, \& Imada, 1997; Matsumoto, Kudoh, Scherer, \& Walbott, 1988). For example, Haidt et al. (1997) found that American and Japanese participants were remarkably similar in the kinds of disgust-eliciting events they described. Further, appraisals about disgust-eliciting situations appear to be similar between American and Japanese participants, being characterized by both groups as unpleasant, due to immoral or improper behavior, and externally caused (Matsumoto et al., 1988). The finding of such similarities in the experience and meaning of disgust suggests the validity of examining disgust propensity in different cultural and ethnic groups.

There have also been findings of some interesting ethnic group differences in the expression and reported experience of disgust. For example, American participants reported feeling that it was appropriate to display disgust in a wider range of situations than Japanese participants (Safdar et al., 2009). Two intrantional studies have examined disgust propensity in Asian Americans: preliminary intranational findings suggest that levels of disgust propensity may differ between Asian Americans and European Americans, with Asian Americans reporting stronger disgust propensity (Haidt, McCauley, \& 
Rozin, 1994; Hirai \& Vernon, 2011). Based on these international and intranational studies, it cannot yet be conclusively determined to what extent ethnic group membership influences reported disgust propensity and it is not clear in what ways and how such ethnic group influences, if any, may impact the relationship of disgust propensity with animal phobic distress.

There is also evidence for gender differences in reported disgust, with American women scoring higher than men on overall disgust propensity and specific domains such as animals (Haidt et al., 1994; Olatunji et al., 2007). However, ethnicity and gender need to be examined together in the study of disgust propensity.

Studying ethnicity and gender simultaneously is important for understanding their interaction. Recent findings from Hirai and Vernon (2011) suggest that there may be an ethnicity by gender interaction for some disgust propensity domains: they found that European Americans showed a gender difference on the three disgust propensity domains examined, whereas a gender difference for Asian Americans was present only for the core disgust domain encompassing food, body products, and animal-related disgust elicitor domains. In all cases of gender differences, women reported higher levels of disgust propensity than men. The specific disgust propensity domains of animal and non-animal elicitors were not examined by Hirai and Vernon (2011). The current research will be the first to test ethnicity by gender interactions for spider and snake distress and animal and non-animal disgust propensity.

\section{Hypotheses}

We hypothesized that: (1) Asian Americans would report more severe spider and snake phobic distress and disgust propensity, in line with prior related research findings (Barker-Collo, 2003; Haidt et al., 1994); (2) women would report more phobic distress and disgust propensity than men, following previous findings with Western samples (Fredrikson et al., 1996; Haidt et al., 1994); (3) European Americans, but not Asian Americans, would display the expected gender difference in spider and snake phobic distress and disgust propensity, parallel to some of Hirai and Vernon's (2011) findings; (4) both animal and nonanimal disgust propensity would be correlated with spider and snake distress in both groups, consistent with Vernon and Berenbaum's (2008) findings for spider distress; and (5) the animal disgust domain would be associated with spider and snake distress above and beyond non-animal disgust propensity for Asian Americans and European Americans, as has been found for spider phobic distress with a primarily European American sample (Vernon \& Berenbaum, 2008).

\section{Method}

\section{Participants}

Participants were 219 Asian American and 581 European American college students from a psychology department subject pool. In order to focus exclusively on the effects of ethnicity without the additional complication of differing countries of origin, those identifying themselves as international Asian students (e.g., Korean, Chinese) were excluded from the present sample (there were no participants who identified themselves as international European students). The Asian American group was 57.1\% female and ranged in age from 18 to $34(M=20.3)$. The European American group was 59.7\% female and between 18 to 47 years old $(M=19.9)$. The groups did not differ in gender. Asian Americans tended to be older, $t(798)=2.33, p<.05$, although the practical significance of this group difference was small (Cohen's $d=.21$; Cohen, 1992). 


\section{Procedure}

Participants completed a battery of questionnaires in a larger ongoing study, including a demographic questionnaire, the Spider Phobia Questionnaire, the Snake Phobia Questionnaire, and the Disgust Emotion Scale. Participants completed questionnaires in the aforementioned order, signed informed consent forms, and received extra credit in participating Psychology classes for participation.

\section{Measures}

The demographic questionnaire asked participants to report age, sex (male $=1$, female $=2$ ), and ethnicity.

The Spider Phobia Questionnaire (SPQ; Klorman et al., 1974) and Snake Phobia Questionnaire (SNAQ; Klorman et al., 1974) measure behavioral, cognitive, and emotional responses characteristic of spider and snake distress, respectively. The SPQ has 31 items and the SNAQ has 30 items. The positively and negatively keyed items are rated as "true" or "false." For the SPQ, reported test-retest reliability over a three week period is high, $r=.94$, reported internal consistency is generally high, and scores are significantly associated with spider avoidance behavior (Muris \& Merckelbach, 1996). Similarly for the SNAQ, high test-retest reliability, $r=.84$, and internal consistency have been reported and snake avoidance is related to SNAQ scores (Hunt et al., 2006; Fredrikson, 1983). Alphas were high in the present study for Asian Americans ( $\alpha=.91$ for SPQ, $\alpha=.92$ for SNAQ) and European Americans $(\alpha=$ .92 for SPQ and SNAQ).

The Disgust Emotion Scale (DES; Walls \& Kleinknecht, 1996) measures disgust propensity to five domains of potential disgust elicitors: small animals, food, odors, mutilation and death, and injection and blood draws. Each domain subscale contains 6 items rated on a 5-point scale $(0=$ no disgust or repugnance; $4=$ extreme disgust or repugnance). Previous internal consistencies for subscales have ranged from .73 to .87 and small to moderate correlations have been reported with the subscales on another disgust sensitivity measure (Olatunji, Williams, Lohr, \& Sawchuk, 2005; Walls \& Kleinknecht, 1996).

In the present analyses, the 6-item small animal domain subscale and an aggregate of the remaining four disgust domains, referred to as non-animal disgust in the present paper, were calculated. In addition, for correlation and regression analyses the inclusion of snake and spider items in the small animal subscale might inflate associations with snake distress and spider distress scores, respectively. Thus, two 5-item animal subscales were calculated, one removing the spider item and the other removing the snake item. Internal consistencies for the Asian Americans were .94 for the non-animal aggregate, .82 for the 6-item animal subscale, .79 for the animal subscale without the snake item, and .79 for the animal subscale without the spider item. For the European Americans, alphas were .94 for the non-animal aggregate, .78 for the 6 -item animal subscale, .75 for the animal subscale without the snake item, and .74 for the animal subscale without the spider item. 


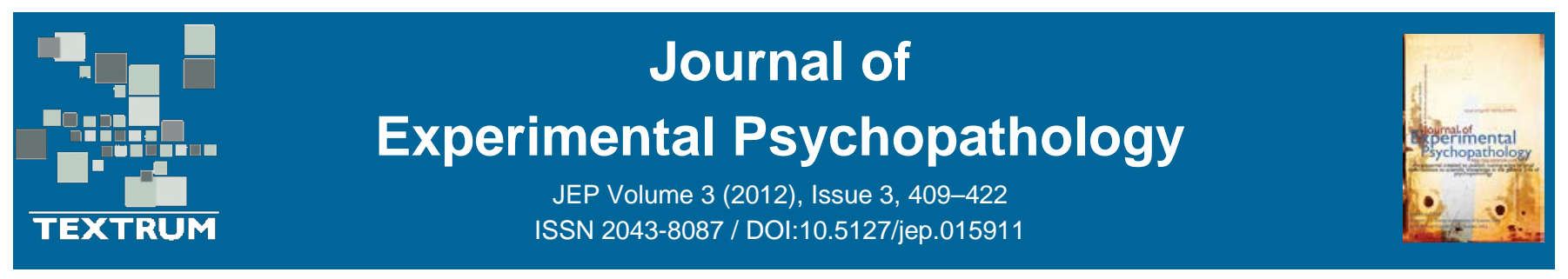

\section{Results}

Table 1: Descriptive Statistics for All Variables by Ethnic Group and Gender

\begin{tabular}{|c|c|c|c|c|c|c|c|c|c|c|c|}
\hline & \multicolumn{4}{|c|}{ Asian American $(N=219)$} & \multicolumn{4}{|c|}{ European American $(N=581)$} & \multicolumn{3}{|c|}{ Group Comparisons } \\
\hline & \multicolumn{2}{|c|}{$\begin{array}{c}\text { Female } \\
(n=125)\end{array}$} & \multicolumn{2}{|c|}{$\begin{array}{c}\text { Male } \\
(n=94)\end{array}$} & \multicolumn{2}{|c|}{$\begin{array}{c}\text { Female } \\
(n=347)\end{array}$} & \multicolumn{2}{|c|}{$\begin{array}{c}\text { Male } \\
(n=234)\end{array}$} & \multirow{2}{*}{$\begin{array}{c}\text { Gender } \\
F(1,796)\end{array}$} & \multirow{2}{*}{$\begin{array}{l}\text { Ethnicity } \\
F(1,796)\end{array}$} & \multirow{2}{*}{$\begin{array}{c}\begin{array}{c}\text { Ethnicity } \\
\text { Gender }\end{array} \\
F(1,796)\end{array}$} \\
\hline & $M$ & $(S D)$ & $M$ & $(S D)$ & $M$ & $(S D)$ & $M$ & $(S D)$ & & & \\
\hline Spider phobia & $12.02^{a, b}$ & $(7.34)$ & $10.00^{a, c}$ & (6.53) & $12.24^{b}$ & $(7.29)$ & $7.76^{\mathrm{c}}$ & $(5.86)$ & $35.06^{\star \star \star}$ & $3.34^{\dagger}$ & $4.95^{\star}$ \\
\hline Snake phobia & $11.62^{\mathrm{a}}$ & $(7.65)$ & $9.90^{\mathrm{a}}$ & $(6.98)$ & $9.33^{\mathrm{a}}$ & $(7.47)$ & $5.78^{\mathrm{b}}$ & $(5.42)$ & $22.22^{\star \star *}$ & $33.02^{\star * \star}$ & 2.61 \\
\hline Non-animal disgust propensity & $60.91^{\mathrm{a}}$ & $(17.41)$ & $56.92^{\mathrm{a}}$ & (17.59) & $57.63^{\mathrm{a}}$ & (16.13) & $47.66^{\mathrm{b}}$ & $(14.76)$ & $29.07^{\star *}$ & $23.41^{\star \star *}$ & $5.32^{*}$ \\
\hline Animal disgust propensity & $13.37^{\mathrm{a}}$ & $(4.67)$ & $12.18^{a, b}$ & $(5.33)$ & $11.25^{\mathrm{b}}$ & $(4.20)$ & $9.36^{\mathrm{c}}$ & $(3.49)$ & $20.44^{\star \star \star}$ & $52.75^{\star \star \star}$ & 1.06 \\
\hline
\end{tabular}

Note: Group comparisons represent MANOVA between-subjects effects. Follow-up ANOVA results are displayed such that groups with different superscripts are significantly different at $p<.05$ level.

$+p<.07 .{ }^{\star} p<.05 .{ }^{\star *} p<.01 .{ }^{* \star *} p<.001$. 


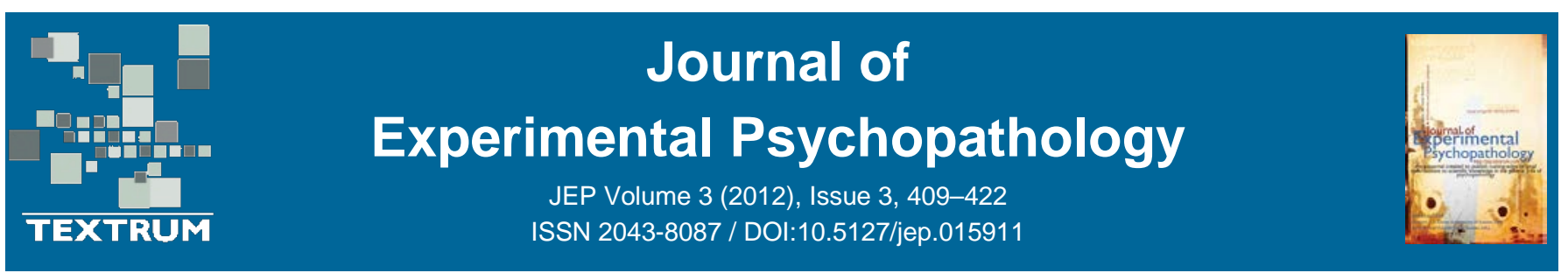

\section{Ethnicity and Gender Differences}

Descriptive statistics for all measures by ethnic group and gender are presented in Table 1. To test for ethnicity and gender effects, we first conducted a 2 (ethnic group) $\times 2$ (gender) $\times 4$ (spider distress, snake distress, non-animal disgust propensity, animal disgust propensity) MANOVA. The MANOVA revealed significant main effects for ethnicity and gender, $F s(4,793)=15.72$ and 13.73 , respectively, $p s$ $<.001$, and a significant ethnicity $\times$ gender interaction, $F(4,793)=3.09, p<.05$. Gender main effects were found for all variables, with females reporting more distress and disgust propensity than males. Main effects of ethnic group were found for snake distress and animal and non-animal disgust propensity, and there was a trend for an ethnicity effect for spider distress; in all cases Asian Americans reported higher levels of distress and disgust propensity than European Americans. Ethnicity $\times$ gender interaction effects were found for spider distress and non-animal disgust propensity. ${ }^{1}$

As this study is the first of its kind, follow-up one-way ANOVAs (ethnicity and gender groups: Asian American males, Asian American females, European American males, and European American females) were conducted to examine interaction effects. The ANOVAs indicated significant ethnicity and gender group differences for all variables. Generally, European American males scored significantly lower than the other three groups. For non-animal disgust propensity and snake distress scores the difference between European American males and all other participants was the only significant difference. For all distress and disgust propensity scores there was a gender difference among European Americans, but not among Asian Americans.

\section{Correlations of Disgust Propensity with Spider and Snake Phobic Distress}

To examine relationships between gender, age, disgust propensity, and distress scores for the ethnic groups, bivariate correlations were conducted separately for Asian Americans and European Americans, as presented in Table 2. For European Americans, spider and snake distress were associated with gender (male $=1$, female $=2$ ) but not age. For Asian Americans, gender was correlated with spider distress and age was correlated with snake distress. Within both groups, all correlations were significant between distress and disgust propensity.

Next the snake and spider items were removed from the DES animal subscale and examined separately, as their inclusion in the subscale was expected to inflate associations with the relevant distress score. Not surprisingly, Asian American's and European American's reported disgust to the spider item was highly correlated with SPQ scores and disgust to the snake item was highly correlated with SNAQ scores. Nonetheless, the DES animal domain score calculated without the spider or snake items continued to be strongly related to SPQ and SNAQ scores, respectively, in both groups.

\footnotetext{
${ }^{1}$ To examine the effect sizes of the significant MANOVA main effects and interactions, eta squared was calculated. Cohen (1988) has suggested that 0.0099 represents a small effect and 0.0588 a medium effect for eta squared. In the current study ethnicity main effect sizes ranged from .030 to .065 , gender main effect sizes ranged from .023 to .042 , and significant ethnicity by gender interaction effect sizes ranged from .006 to .007 . The effect size for ethnic group for animal disgust propensity was the largest (eta squared $=.065)$ and would be considered a medium effect. Most other effects sizes were small.
} 


\begin{tabular}{lcccc}
\hline & \multicolumn{2}{c}{ Spider Phobia } & \multicolumn{2}{c}{ Snake Phobia } \\
\cline { 2 - 5 } & $\begin{array}{c}\text { Asian } \\
\text { American }\end{array}$ & $\begin{array}{c}\text { European } \\
\text { American }\end{array}$ & $\begin{array}{c}\text { Asian } \\
\text { American }\end{array}$ & $\begin{array}{c}\text { European } \\
\text { American }\end{array}$ \\
\hline Gender & $.14^{\star}$ & $.31^{\star \star \star}$ & .12 & $.25^{\star \star \star}$ \\
Age & .01 & -.07 & $.16^{\star}$ & .05 \\
Non-animal disgust propensity & $.33^{\star \star \star}$ & $.42^{\star \star \star}$ & $.34^{\star \star \star}$ & $.40^{\star \star \star}$ \\
Animal disgust propensity & $.48^{\star \star \star}$ & $.58^{\star \star \star}$ & $.60^{\star \star \star}$ & $.60^{\star \star \star}$ \\
Spider disgust item & $.71^{\star \star \star}$ & $.76^{\star \star \star}$ & $.33^{\star \star \star}$ & $.29^{\star \star \star}$ \\
Snake disgust item & $.32^{\star \star \star}$ & $.31^{\star \star \star}$ & $.74^{\star \star \star}$ & $.78^{\star \star \star}$ \\
Animal disgust propensity & $.36^{\star \star \star}$ & $.43^{\star \star \star}$ & $.50^{\star \star \star}$ & $.46^{\star \star \star}$ \\
\hline
\end{tabular}

${ }^{1}$ The spider item was removed from the animal disgust propensity domain for correlations with spider phobia and the snake item was removed from the animal disgust propensity domain for correlations with snake phobia.

${ }^{*} p<.05 .{ }^{* \star *} p<.001$.

\section{Independent Relationships of Disgust Propensity with Spider and Snake Phobic Distress}

To examine whether animal disgust propensity is related to spider and snake distress over and above non-animal disgust propensity in the two ethnic groups, and to control for the influence of gender, hierarchical regression analyses were conducted for the ethnic groups separately with spider phobic distress and snake phobic distress as the dependent variables. These analyses were performed by ethnic group because group differences on animal distress scores were found. Given our findings of gender differences in level of phobic distress and disgust propensity, gender was entered in the first step. Since age was associated with snake distress for Asian Americans, age was also entered into the first step for the snake distress regression for Asian Americans. The non-animal disgust propensity score was added in the second step and then in the third step the animal disgust propensity subscale without the spider item for the spider distress regressions and without the snake item for the snake distress regressions were added. Regression results are shown in Table 3.

As expected, animal disgust propensity was strongly and uniquely related to both spider and snake distress scores in both ethnic groups, even when removing the spider or snake item from the animal disgust domain. ${ }^{2}$ However, in the European American group non-animal disgust propensity contributed to variance in spider and snake distress scores independent of the strong contribution of disgust propensity to small animals. In contrast, among Asian Americans, non-animal disgust propensity was not significantly associated with spider and snake distress independent of animal disgust propensity.

For the demographic variables, only among European Americans was gender associated with spider and snake distress independent of animal and non-animal disgust propensity, with a positive association that indicates higher distress scores among females. For Asian Americans, gender was not related to distress scores independent of disgust propensity and gender was not significantly related to snake distress even when it was the only variable in the model. Among Asian Americans, age was related to

\footnotetext{
${ }^{2}$ Parallel hierarchical regression analyses were run with the full DES animal subscale, including the spider and snake items, and as would be expected the full animal subscale was strongly uniquely associated with phobic distress scores for both groups (for spider distress: for Asian Americans $\beta=.52$, for European Americans $\beta=.60$; for snake distress: for Asian Americans $\beta=.77$, for European Americans $\beta=.65)$.
} 
snake distress independent of gender and non-animal disgust propensity, but not independent of animal disgust propensity.

Table 3: Hierarchical Regression Analyses Predicting Spider and Snake Phobia Scores by Ethnic Group

\begin{tabular}{|c|c|c|c|c|c|}
\hline & & \multicolumn{2}{|c|}{ Spider Phobia } & \multicolumn{2}{|c|}{ Snake Phobia } \\
\hline & & $\begin{array}{c}\text { Asian } \\
\text { American }\end{array}$ & $\begin{array}{l}\text { European } \\
\text { American }\end{array}$ & $\begin{array}{c}\text { Asian } \\
\text { American }\end{array}$ & $\begin{array}{l}\text { European } \\
\text { American }\end{array}$ \\
\hline \multirow[t]{3}{*}{1} & $\beta$ for gender & $.14^{\star}$ & $.31^{\star \star \star}$ & $.13^{\dagger}$ & $.25^{\star \star \star}$ \\
\hline & $\beta$ for age & & & $.17^{\star}$ & \\
\hline & Model $R^{2}$ & $.02^{*}$ & $.10^{\star \star \star}$ & $.04^{*}$ & $.06^{\star \star \star}$ \\
\hline \multirow[t]{5}{*}{2} & $\beta$ for gender & $.11^{*}$ & $.20^{\star \star \star}$ & .09 & $.14^{\star \star \star}$ \\
\hline & $\beta$ for age & & & $.17^{\star \star}$ & \\
\hline & $\beta$ for non-animal disgust propensity & $.32^{\star \star \star}$ & $.36^{\star \star \star}$ & $.33^{\star \star \star}$ & $.36^{\star \star \star}$ \\
\hline & $R^{2}$ change & $.10^{\star \star \star}$ & $.11^{\star \star \star}$ & $.11^{\star \star \star}$ & $.12^{\star \star \star}$ \\
\hline & Model $R^{2}$ & $.12^{\star \star \star}$ & $.21^{\star \star \star}$ & $.15^{\star \star \star}$ & $.18^{\star \star \star}$ \\
\hline \multirow[t]{6}{*}{3} & $\beta$ for gender & .10 & $.20^{\star \star \star}$ & .07 & $.14^{\star \star \star}$ \\
\hline & $\beta$ for age & & & .10 & \\
\hline & $\beta$ for non-animal disgust propensity & .13 & $.18^{\star \star}$ & -.08 & $.11^{*}$ \\
\hline & $\beta$ for animal disgust propensity ${ }^{1}$ & $.25^{\star \star}$ & $.26^{\star \star \star}$ & $.54^{\star \star \star}$ & $.34^{\star \star \star}$ \\
\hline & $R^{2}$ change & $.03^{\star \star}$ & $.04^{\star \star \star}$ & $.12^{\star \star \star}$ & $.06^{\star \star \star}$ \\
\hline & Model $R^{2}$ & $.15^{\star \star \star}$ & $.25^{\star \star \star}$ & $.27^{\star \star \star}$ & $.24^{\star \star \star}$ \\
\hline
\end{tabular}

${ }^{1}$ The spider item was removed from the animal disgust propensity domain for regressions with spider phobia and the snake item was removed from the animal disgust propensity domain for regressions with snake phobia.

${ }^{\dagger} p<.06 .{ }^{*} p<.05 .{ }^{\star *} p<.01 .{ }^{* \star *} p<.001$.

\section{Discussion}

The differences between Asian Americans and European Americans found in the current investigation provide evidence for the importance of ethnic group membership for understanding spider and snake phobic distress, disgust propensity, and their interrelationships, as well as gender differences among them. Previous research has typically examined the effects of either ethnicity alone or gender alone on animal phobic distress or disgust propensity and the current study replicates previous findings in such research. As predicted, Asian Americans in our sample reported more snake and spider distress symptoms and disgust propensity than did European Americans, consistent with related preliminary findings of higher reported phobic anxiety and fear of animals and stronger disgust propensity reported by Asian ethnic groups (Barker-Collo, 2003; Davey et al., 1998; Haidt et al., 1994; Hirai \& Vernon, 2011). Also as hypothesized, overall, females reported more phobic distress symptoms and disgust propensity than males, consistent with previous research (Fredrikson et al., 1996; Haidt et al., 1994). However, these differences were modified by ethnicity by gender interactions. We found ethnicity by gender interactions in which European American males reported the fewest phobic distress symptoms and the lowest disgust propensity. Our interaction results parallel those previously reported for some domains of disgust propensity (Hirai \& Vernon, 2011), but this is the first study to find such an effect for animal and non-animal disgust propensity and spider and snake phobic distress. Our interaction findings suggest that to understand spider and snake distress and disgust propensity, an examination of ethnicity or 
gender alone appears to be insufficient. For example, the gender differences present for spider distress in the total sample were actually being driven by the European Americans and were not present among Asian Americans. The follow-up ANOVA results suggested gender differences on all phobic distress and disgust propensity measures for European Americans but no such gender differences for Asian Americans.

The present results indicate robust gender effects for the European Americans, but it is not clear whether they reflect an actual difference in experience or some other gender phenomenon, such as less willingness on the part of European American males to report animal phobic distress and disgust propensity. It would be useful for future research to employ a wider array of distress and emotion measures, some of which may be less susceptible to social desirability and reporting biases, such as physiological responses, facial expressions, or avoidance behavior, to help add to our understanding of the current gender effects. At a minimum, our findings suggest that typical gender norms on instruments such as the SPQ might need to be specified according to ethnic group, as the current results suggest that gender cutoffs may not be appropriate for all ethnic groups.

The effect of ethnic group membership on reactions to animals warrants additional discussion. For example, the present research found that within each gender, the European Americans reported less animal disgust propensity than their Asian American counterparts. It may be the case that the Asian Americans in our sample were relatively less likely to have had exposure to animals than the European Americans. It also seems probable that there are ethnic, cultural, social, and religious beliefs about specific animals that influence disgust propensity. It may be the case that those from collectivistic backgrounds, such as the Asian Americans in the present sample, will report more disgust propensity than those from individualistic backgrounds given theories of the social and moral meanings of disgust (Haidt et al., 1997). Future research should examine whether individual differences in familiarity with and knowledge about animals, as well as ethnic group differences in beliefs about animals, is related to animal disgust propensity.

In terms of ethnic group similarities, our results suggest that disgust propensity, particularly the animal domain, is strongly related to both spider and snake distress among Asian Americans and European Americans, extending previous findings with largely European American samples (Klieger \& Siejak, 1997; Vernon \& Berenbaum, 2008). When the independence of associations in the current study was tested in regression analyses, as hypothesized, disgust propensity to animals was uniquely associated with both spider and snake distress scores over and above non-animal disgust propensity for both ethnic groups. Further, animal disgust propensity accounted for a large portion of the variance in spider distress and snake distress scores for both ethnic groups. These relationships existed even though the spider or snake item was removed from the animal disgust propensity subscale, suggesting that such associations are not specific to disgust to spiders and snakes but likely reflects the importance of disgust propensity to animals in general. Our results are consistent with previous findings indicating that associations between animal disgust propensity and spider distress may be independent of the effects of other disgust domains (de Jong \& Merckelbach, 1998; Vernon \& Berenbaum, 2008) and extend such findings to snake distress and Asian Americans, suggesting the robust nature of these relationships across ethnic group and type of animal phobia symptoms.

Although we found strong correlations between distress and disgust propensity for both groups, Asian and European Americans differed in the independence of such relationships in regression analyses. For European Americans, non-animal disgust propensity was uniquely associated with spider and snake distress independent of animal disgust propensity and gender. For the Asian Americans, non-animal disgust propensity was not uniquely related to spider and snake distress independent of animal disgust 
propensity. These results suggest the influence of ethnic group membership on relationships between disgust propensity and animal distress. For example, it may be the case that for European Americans the relationship of disgust propensity and animal distress is fairly generalized, whereas for Asian Americans it is specific to animal disgust propensity. Future research might examine the specificity of disgust propensity in ethnic groups with different disgust socialization practices, such as those from collectivistic and individualistic societies.

When the current results among European Americans are viewed in concert with the two previous studies examining the relative association of non-animal disgust propensity and spider distress in Western samples (de Jong \& Merckelbach, 1998; Vernon \& Berenbaum, 2008), no clear picture emerges for this group. In our European American sample non-animal disgust propensity was a unique predictor of animal distress, whereas the two prior studies with Western samples of undifferentiated ethnic backgrounds did not find a unique contribution of other disgust propensity domains to spider distress variance. These differences may be because the previous studies used a different disgust propensity measure, had dissimilar samples, and included a host of other variables in their regression analyses. Although it is apparent that various disgust domains are associated with spider and snake distress, both in the current research and in previous investigations (de Jong \& Merckelbach, 1998; Tolin et al., 1997; Vernon \& Berenbaum, 2008), future research is needed to specify conditions and samples in which non-animal disgust propensity domains are uniquely associated with distress symptom severity and how this might affect treatment approaches with different groups. For example, in groups in which non-animal disgust propensity is strongly and robustly associated with animal phobic distress, it may be important to include treatment interventions aimed at decreasing general disgust propensity as well as those targeting reactions to the phobic stimulus.

Another important contribution of the present study is the information it provides about snake distress' relationships with animal and non-animal disgust propensity, and the ethnic group and gender differences in level of snake distress. Although there is a body of research on spider distress and disgust propensity, there is a dearth of such research on snake distress. Klieger and Siejak (1997) reported an association between snake distress and food-related disgust propensity, and the current study demonstrates associations of snake distress with animal and non-animal disgust propensity among men and women of European American and Asian American descent. The present study also builds on a preliminary report of ethnic group differences in animal phobia symptom level (Barker-Collo, 2003) to specifically demonstrate higher snake distress symptom severity among women and Asian Americans relative to men and European Americans, respectively.

Although the current study provides important information about disgust propensity and animal distress among Asian Americans, it would be useful for future research to explore potential differences within this rather heterogeneous group. For example, previous international research has found different rates of phobia symptoms in psychiatric outpatient samples from China, Indonesia, Japan, Taiwan, and Thailand (Tseng et al., 1990) and has found significant differences in animal fear ratings among Asian samples (e.g., with Koreans reporting less fear of snakes than Japanese, Hong Kong, and Indian samples; Davey et al., 1998). At present we are not aware that any phobia or anxiety research has made such distinctions within Asian American populations of varying Asian descent.

Another important next step is examining mechanisms that may be responsible for ethnicity and gender influences on disgust propensity and animal distress, including individual differences in individualism and collectivism, masculinity and femininity, structural and power differences, socioeconomic status, acculturation, and ethnic identity (Arrindell et al., 2003; Brody, 1997; Fischer, Rodriguez Mosquera, van Vianen, \& Manstead, 2004; Kitayama \& Markus, 1992; Mesquita \& Frijda, 1992; Triandis, 1995). 
Additionally, it will be important to examine the psychometric properties of anxiety disorder and emotion measures in different ethnic groups. Although there is some research that suggests the validity of disgust propensity concepts and measures cross-culturally (Brandt \& Boucher, 1985; Boucher \& Brandt, 1981; Haidt et al., 1997; Matsumoto et al., 1988), it is not known whether animal phobia and disgust measures are equally psychometrically sound in different ethnic groups.

The present study serves as an initial step in cross-cultural individual differences and phobia research, documenting ethnic group and gender differences and ethnicity by gender interactions in animal phobic distress and disgust propensity as well as ethnic group similarities in relationships between animal distress and animal disgust propensity. This study suggests that gender differences in distress symptoms and disgust propensity present among European Americans may not be present in all ethnic groups, as they were not found among Asian Americans. It would be valuable for future phobia and individual difference research to carefully delineate ethnic group and gender effects among different phobia types and different domains of disgust elicitors. Models of animal phobic distress and disgust propensity based solely or largely on European American samples will need to be tailored to Asian Americans.

\section{References}

Arrindell, W.A., Eisemann, M., Richter, J., Oei, T.P.S., Caballo, V.E., van der Ende, J., ... Hatzichristou, C. (2003). Masculinity-femininity as a national characteristic and its relationship with national agoraphobic fear levels: Fodor's sex role hypothesis revitalized. Behaviour Research and Therapy, 41, 795-807. http://dx.doi.org/10.1016/S0005-7967(02)00188-2

Barker-Collo, S.L. (2003). Culture and validity of the Symptom Checklist-90-Revised and profile of mood states in a New Zealand student sample. Cultural Diversity and Ethnic Minority Psychology, 9, 185196. http://dx.doi.org/10.1037/1099-9809.9.2.185

Berenbaum, H., Raghavan, C., Le, H., Vernon, L.L., \& Gomez, J.J. (2003). Taxonomy of emotional disturbances. Clinical Psychology: Science and Practice, 10, 206-226. http://dx.doi.org/10.1093/clipsy.bpg011

Boucher, J.D., \& Brandt, M.E. (1981). Judgment of emotion: American and Malay antecedents. Journal of Cross-Cultural Psychology, 12, 272-283. http://dx.doi.org/10.1177/0022022181123002

Brandt, M.E., \& Boucher, J.D. (1985). Judgment of emotions from the antecent situations in three cultures. In I.R. Lagunes \& Y.H. Poortinga (Eds.), From a different perspective: Studies of behavior across cultures (pp.348-362). Lisse, The Netherlands: Swets \& Zeitlinger.

Brody, L.R. (1997). Gender and emotion: Beyond stereotypes. Journal of Social Issues, 53, 369-394. http://dx.doi.org/10.1111/j.1540-4560.1997.tb02448.x

Cohen, J. (1992). A power primer. Psychological Bulletin, 112, 155-159. http://dx.doi.org/10.1037/00332909.112.1.155

Cohen, J. (1988). Statistical power analysis for the behaviorial sciences (2nd ed.)

Davey, G.C.L., McDonald, A.S., Hirisave, U., Prabhu, G.G., Iwawaki, S., Jim, C.I., ... Reimann, B.C. (1998). A cross-cultural study of animal fears. Behaviour Research and Therapy, 36, 735-750. http://dx.doi.org/10.1016/S0005-7967(98)00059-X

Eid, M., \& Diener, E. (2001). Norms for experiencing emotions in different cultures: Inter- and intranational differences. Journal of Personality and Social Psychology, 81, 869-885. http://dx.doi.org/10.1037/0022-3514.81.5.869

Fischer, A. H., Rodriguez Mosquera, P. M., van Vianen, A. E. M., \& Manstead, A. S. R. (2004). Gender and culture differences in emotion. Emotion, 4(1), 87-94. http://dx.doi.org/10.1037/1528-3542.4.1.87 
Fredrikson, M. (1983). Reliability and validity of some specific fear questionnaires. Scandinavian Journal of Psychology, 24, 331-334. http://dx.doi.org/10.1111/j.1467-9450.1983.tb00507.x

Fredrikson, M., Annas, P., Fischer, H., \& Wik, G. (1996). Gender and age differences in the prevalence of specific fears and phobias. Behaviour Research and Therapy, 34(1), 33-39. http://dx.doi.org/10.1016/0005-7967(95)00048-3

Haidt, J., McCauley, C., \& Rozin, P. (1994). Individual differences in sensitivity to disgust: A scale sampling seven domains of disgust elicitors. Personality and Individual Differences, 16, 701-713. http://dx.doi.org/10.1016/0191-8869(94)90212-7

Haidt, J., Rozin, P., McCauley, C., \& Imada, S. (1997). Body, psyche, and ethnicity: The relationship between disgust and morality. Psychology and Developing Societies. Special Issue: Cultural Constructions and Social Cognition: Emerging Themes, 9(1), 107-131. http://dx.doi.org/10.1177/097133369700900105

Hirai, M., \& Vernon, L. (2011). The role of disgust propensity in blood-injection-injury phobia: Comparisons between Asian Americans and Caucasian Americans. Cognition and Emotion, 25(8), 1500-1509. http://dx.doi.org/10.1080/02699931.2010.547564

Hunt, M., Bylsma, L., Brock, J., Fenton, M., Goldberg, A., Miller, R., ... Urgelles, J. (2006). The role of imagery in the maintenance and treatment of snake fear. Journal of Behavior Therapy and Experimental Psychiatry, 37(4), 283-298. http://dx.doi.org/10.1016/j.jbtep.2005.12.002

Jong, P.J. de, \& Merckelbach, H. (1998). Blood-injection-injury phobia and fear of spiders: Domain specific individual differences in disgust sensitivity. Personality and Individual Differences, 24, 153158. http://dx.doi.org/10.1016/S0191-8869(97)00178-5

Kessler, R.C., Chiu, W.T., Demler, O., \& Walters, E.E. (2005). Prevalence, severity, and comorbidity of 12-month DSM-IV Disorders in the National Comorbidity Survey Replication. Archives of General Psychiatry, 62, 617-627. http://dx.doi.org/10.1001/archpsyc.62.6.617

Kitayama, S., \& Markus, H.R. (Eds.). (1992). Emotion and culture. Washington, DC: American Psychological Association.

Klieger, D.M., \& Siejak, K.K. (1997). Disgust as the source of false positive effects in the measurement of ophidiophobia. The Journal of Psychology, 131, 371-382.

http://dx.doi.org/10.1080/00223989709603523

Klorman, R., Weerts, T.C., Hastings, J.E., Melamed, B.G., \& Lang, P. (1974). Psychometric description of some specific-fear questionnaires. Behavior Therapy, 5, 401-409. http://dx.doi.org/10.1016/S00057894(74)80008-0

Matsumoto, D., Kudoh, T., Scherer, K., \& Walbott, H. (1988). Antecedents of and reactions to emotions in the United States and Japan. Journal of Cross-Cultural Psychology, 19(3), 267-286. http://dx.doi.org/10.1177/0022022188193001

Mesquita, B., \& Frijda, N.H. (1992). Cultural variations in emotions: A review. Psychological Bulletin, 112, 179-204. http://dx.doi.org/10.1037/0033-2909.112.2.179

Muris, P., \& Merckelbach, H. (1996). A comparison of two spider fear questionnaires. Journal of Behavior Therapy and Experimental Psychiatry, 27, 241-244. http://dx.doi.org/10.1016/S00057916(96)00022-5

Olatunji, B. O., Williams, N. L., Lohr, J. M., \& Sawchuk, C. N. (2005). The structure of disgust: Domain specificity in relation to contamination ideation and excessive washing. Behaviour Research and Therapy, 43(8), 1069-1086. http://dx.doi.org/10.1016/j.brat.2004.08.002

Olatunji, B.O., Williams, N.L., Tolin, D.F., Abramowitz, J.S., Sawchuck, C.N., Lohr, J.M., \& Elwood, L.S. (2007). The disgust scale: Item analysis, factor structure, and suggestions for refinement. Psychological Assessment, 19, 281-297. http://dx.doi.org/10.1037/1040-3590.19.3.281 
Overveld, W.J.M. van, de Jong, P.J., Peters, M.L., Cavanagh, K., \& Davey, G.C.L. (2006). Disgust propensity and disgust sensitivity: Separate constructs that are differentially related to specific fears. Personality and Individual Differences, 41, 1241-1252. http://dx.doi.org/10.1016/j.paid.2006.04.021

Rozin, P., \& Fallon, A. (1987). A perspective on disgust. Psychological Review, 94, 23-41. http://dx.doi.org/10.1037/0033-295X.94.1.23

Safdar, S., Friedlmeier, W., Matsumoto, D., Yoo, S.H., Kwantes, C.T., Kakai, H., \& Shigemasu, E. (2009). Variations of emotional display rules within and across cultures: A comparison between Canada, USA, and Japan. Canadian Journal of Behavioural Science, 41(1), 1-10. http://dx.doi.org/10.1037/a0014387

Scherer, K.R., \& Wallbott, H.G. (1994). Evidence for universality and cultural variation of differential emotion response patterning. Journal of Personality and Social Psychology, 66, 310-328. http://dx.doi.org/10.1037/0022-3514.66.2.310

Tolin, D.F., Lohr, J.M., Sawchuk, C.N., \& Lee, T.C. (1997). Disgust and disgust sensitivity in bloodinjection-injury and spider phobia. Behavior Research and Therapy, 35, 949-953. http://dx.doi.org/10.1016/S0005-7967(97)00048-X

Triandis, H.C. (1995). Individualism and collectivism. Boulder, CO: Westview Press.

Tseng, W., Asai, M., Jieqiu, L., Wibulswasdi, P., Suryani, L.K., Wen, J., ... Heiby, E. (1990). Multicultural study of minor psychiatric disorders in Asia: Symptom manifestations. The International Journal of Social Psychiatry, 36(4), 252-264. http://dx.doi.org/10.1177/002076409003600403

U.S. Census Bureau (2010). United States Census 2010. http://2010.census.gov.

Vernon, L.L., \& Berenbaum, H. (2008). Fear and disgust propensity in spider phobic distress. Journal of Anxiety Disorders, 22, 1285-1296. http://dx.doi.org/10.1016/j.janxdis.2008.01.009

Vernon, L.L., \& Berenbaum, H. (2002). Disgust and fear in response to spiders. Cognition and Emotion, 16, 809-830. http://dx.doi.org/10.1080/02699930143000464

Walls, M.M., \& Kleinknecht, R.A. (1996). Disgust factors as predictors of blood-injury fear and fainting. Paper presented to the Annual Meeting of the Western Psychological Association, San Jose, CA.

Wells, E.J., Browne, M.A.O., Scott, K.M., McGee, M.A., Baxter, J., \& Kokaua, J. (2006). Prevalence, interference with life and severity of 12 month DSM-IV disorders in Te Rau Hinengaro: The New Zealand Mental Health Survey. Australian and New Zealand Journal of Psychiatry, 40, 845-854. http://dx.doi.org/10.1111/i.1440-1614.2006.01903.x 